\title{
ENTREVISTA COM TULLY EHLERS
}

\section{INTERVIEW WITH TULLY EHLERS}

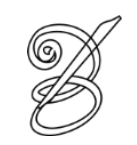

Entrevistada por:

Patrícia Rodrigues COSTA*

Universidade de Brasília, Brasil

ully Ehlers ${ }^{* *}$ é uma tradutora literária brasileira. Atualmente finaliza o bacharelado em
Tradutor e Intérprete na Universidade Nove de Julho (Uninove) enquanto traduz, para
a Pedrazul editora, os oito livros sobre a personagem Anne Shirley de autoria da canadense Lucy Maud Montgomery. Esta obra de Montgomery foi adaptada para cinema e televisão, sendo a adaptação mais recente a série Anne with an E, produzida pela Canadian Broadcasting Corporation (CBC) e disponibilizada em streaming pela Netflix.

RECEBIDO EM: 10 de dezembro de 2019

ACEITO EM: 28 de dezembro de 2019

PUBLICADO EM: janeiro 2020 
1) Você poderia se apresentar para o público que ainda não te conhece?

Bem, me chamo Tully Borba Ehlers de Oliveira, tenho 36 anos, sou gaúcha, de Porto Alegre, e brasiliense e paulista por adoção e casamento. Sou casada há 15 anos com o Israel Carvalho, o herói do meu romance, e mãe de três crianças, Raquel, Miguel e o bebê Benjamin. Sou membro da Igreja Adventista do Sétimo Dia; o fato de ser cristã é parte integral da minha vida, e parte da minha formação como ser humano. Curso a graduação em Tradutor e Intérprete na Uninove, São Paulo, e estou em processo de estudo e preparação para escrever o Trabalho de Conclusão de Curso. Atualmente, moro na Argentina, onde meu marido estuda.

Sou uma fascinada por palavras, pela literatura e pelas línguas estrangeiras, e a Tradução Literária é a melhor maneira de trabalhar com todas as minhas paixões. E por isso, quanto mais estudo e aprendo sobre esta arte, mais apaixonada e impressionada eu fico. Ler e traduzir são também meus maiores hobbies, e escrever pode entrar na lista como uma das coisas que mais amo fazer. Então acho que estou num bom caminho, mesclando todas as coisas que mais amo fazer numa arte só.

2) Desde quando você traduz? Em qual par de língua? Enfim, como você entrou no "mundo da tradução"?

Comecei minha carreira como tradutora literária em novembro de 2014, e trabalho com os pares Inglês/Português-BR e Espanhol/Português-BR.

Para mim, foi como se a tradução caísse no meu colo. Comecei a estudar inglês por minha conta em 2012, que se tornou minha paixão, e soube que tinha encontrado meu caminho, queria trabalhar com a língua inglesa. Depois de me questionar como poderia tornar essa paixão uma profissão, acabei descobrindo a tradução. Mas, como já tinha filhos, meu marido estudando, só ele trabalhando, etc. ficava difícil que eu conseguisse estudar também, então tive que adiar o sonho. Nesta época, passei a fazer parte de um grupo no Facebook chamado Literatura de Época, e foi quando conheci a série Anne of Green Gables produzida pela Sullivan Entretenimen e lançada em 1985, estrelando Megan Follows no papel de Anne Shirley, e Jonathan Crombie como Gilbert Blythe. Apaixonei-me pela série e logo fui em busca dos livros. E foi quando conheci o trabalho da Lucy Maud Montgomery, e fui inspirada por suas palavras. A Anne é, de fato, uma personagem inspiradora e intrigante, e a gente fica sempre querendo mais. Poucas das amigas do grupo já tinham lido o livro Anne of Green Gables, e por isso, eu 
ia postando trechos que eu mesma traduzia no grupo, para que as amigas tivessem acesso. $\mathrm{E}$ assim fiz de todos os 8 livros, os quais li em 10 dias. Neste momento, eu traduzia apenas como lia, escrevendo em bom português, de forma clara, mas sem nenhuma pretensão, apenas para que minhas amigas pudessem ter noção de como eram lindas as continuações da Anne. Quando terminava, fazia resenhas dos livros, e minhas amigas do grupo se empolgavam, então, quando terminei, resolvemos fazer um abaixo assinado, com o intuito de entregar à alguma editora, para que eles tomassem o projeto de traduzir as continuações da série da Anne. Uma das meninas do grupo conhecia a Chirlei Wandekoken, que é a criadora/editora da Pedrazul editora. Esta amiga entregou o abaixo-assinado para ela, que decidiu que a editora iria abraçar o projeto. $\mathrm{E}$ esta mesma amiga me indicou para a Chirlei, pois sabia que eu tinha o sonho de me tornar tradutora. Foi então que a Chirlei entrou em contato comigo, me perguntando se eu tinha interesse de vender para editora as traduções que eu já tinha feito. Expliquei para ela que não tinha traduzido os livros, que não era profissional, que só tinha traduzido trechos para que as meninas tivessem acesso às melhores partes. Ela me pediu que mandasse um capítulo traduzido, como um teste. Chirlei gostou do meu texto, e me perguntou se eu não tinha interesse em traduzir o livro Anne of Green Gables. Fiquei sinceramente sem saber o que dizer, tive medo de aceitar, e não saber como fazer, mas ela me encheu de confiança, dizendo que o texto estava muito bom. E então resolvi encarar o desafio, e iniciei a tradução de Anne of Green Gables em 28 de novembro de 2014. Sempre senti como se tivesse entrado na profissão pela porta dos fundos, pois não tinha nenhuma formação, e meu conhecimento sobre a profissão era limitado ao que lia em grupos de tradutores e blogues etc. Foi muito difícil o começo, até entender como funcionava o processo de traduzir. Tive ajuda de algumas pessoas que me orientaram, mas no mais foi batendo cabeça que aprendi.

3) O que a levou a cursar o bacharelado em Tradutor e Intérprete?

Eu não tinha nenhum curso de formação superior, e, como já sonhava em me tornar profissional, resolvi focar meus esforços na graduação superior em Tradutor e Intérprete diretamente. Também não queria cursar Letras, e correr o risco de passar pelas disciplinas de didática, que realmente não me chamam muito atenção, e para as quais realmente não tenho nenhum talento. Esta é uma vantagem real ao escolher uma profissão depois de estar adulta e já ter um maior conhecimento de si mesmo; a gente sabe o que quer e o que não quer, e o que suporta fazer ou não, e pode concentrar esforços no que a gente realmente quer. 
4) Como foi a experiência de fazer o bacharelado a distância?

Bom, à época, eu morava em Brasília, e o curso que queria fazer ficava em São Paulo, e era totalmente online, salvo provas presenciais ao final de cada bimestre. Então foi a melhor decisão, considerando que tinha as crianças, e para mim seria impossível frequentar aulas diariamente. E posso dizer que as aulas fluíram muito bem, fazíamos trabalhos em grupo, tínhamos boas discussões, pesquisei muito, li muito. Como já tenho essa facilidade para aprender de forma autodidata, para mim acabou sendo o método perfeito. As únicas ressalvas foram a respeito das aulas e trabalhos nas aulas de Interpretação. Eu sou tímida demais para aparecer e ficava envergonhada demais para mandar os vídeos. Mas era o necessário, então foi feito.

5) Tendo ingressado na graduação em Tradução após já ter traduções literárias publicadas, você mudou a maneira de pensar sobre o processo tradutório? Sua formação como tradutora influenciou seu processo tradutório?

Não sei bem ao certo se mudou, acho que seria mais correto dizer que me fez consciente dos porquês tomava determinadas decisões. Eu tinha uma forma meio instintiva de traduzir e escrever. Traduzia como gostaria de ler. E, em termos gerais, continua sendo assim, mas agora eu entendo que existe uma teoria por trás disso, e posso justificar minhas escolhas. Faço uma discussão comigo mesma sobre as melhores abordagens, e o porquê tomo as decisões que tomo de forma instintiva. Sinto que ainda estou no primeiro degrau da minha formação como tradutora profissional, primeiro degrau para entender as tecnicidades da língua e as teorias tradutórias, apesar de já ter uma certa experiência, mas agora pelo menos já sei por que tomo determinadas decisões e porque me parecem as melhores.

6) Você chegou a cursar disciplinas relacionadas à literatura durante a graduação? Como elas ajudaram no seu pensar sobre o papel de tradutores literários ou mesmo a sua atuação como tradutora?

Sim, cursei Literatura Inglesa, Americana e Canadense e Brasileira e Portuguesa. Confesso que as matérias sobre literatura da faculdade foram meio corridas e superficiais. Mas meu amor pela literatura, que vem desde muito cedo, sempre me faz refletir na responsabilidade 
que tenho para com o leitor, na importância da profissão para a literatura, e como seria limitada a visão de mundo dos leitores, que não teriam acesso à literatura estrangeira. Para mim, a literatura é a melhor maneira de conhecer uma outra época, outro lugar, outra cultura, e sendo assim, o tradutor é aquele que torna possível esse conhecimento. Sinto-me privilegiada por trabalhar como tradutora literária, de servir como ponte entre a obra e o leitor.

7) O que você pode nos falar sobre o seu Trabalho de Conclusão de Curso?

Que ainda é um mistério haha. Brincadeiras à parte, eu realmente não tinha ideia do que queria pesquisar até que a professora de Linguística de Corpus da faculdade me deu a sugestão de usar o resultado coletado para um trabalho da disciplina como base para meu TCC. O trabalho consistia em fazer uma análise de corpus de textos em inglês e português, e criar um glossário. E eu tinha interesse em fazer sobre os livros da série da Anne, e criar um glossário sobre os termos encontrados nas obras. Percebemos, após a análise, que não havíamos obtido um número considerável de termos, e foi então que a professora sugeriu que eu usasse esse resultado como base para o TCC. Pesquisei muito, e decidi trabalhar com Análise Estilística da Obra de Lucy Maud Montgomery, baseada em Linguística de Corpus. Ou quem sabe a relevância desse tipo de resultado para o tradutor literário. E é aí que ainda reside minha dúvida. Ainda estou na fase de organização de material, para começar a ler e escrever. Única certeza que tenho é que vou escrever sobre a Maud.

8) Em 2015, foi publicada sua tradução para a obra Anne of Green Gables (1908), da escritora canadense Lucy Maud Montgomery, dois anos antes da estreia da série da Netflix “Anne with an E”. Desde então, a editora Pedrazul tem publicado os demais livros da série tendo você como tradutora. Como surgiu seu interesse pela Obra de Montgomery?

Como expliquei anteriormente, conheci a obra da Maud em 2014, primeiro assistindo a série mais antiga, de 1985, e logo em seguida como leitora, lendo a coleção toda, e me apaixonando de imediato. No momento em que lia as obras, não tinha ideia de que chegaria a ter o privilégio de traduzir as obras completas. Estava contente apenas em traduzir trechos que me encantavam para que minhas amigas tivessem acesso às palavras tão apaixonantes e inspiradoras da Maud. 
9) Você saberia dizer o que levou a editora a publicar os oito livros da série que estão em domínio público, sendo a primeira editora brasileira a fazê-lo?

A princípio, tivemos bem pouco sucesso com os dois primeiros livros. O pessoal tinha a ideia de que eram livros escritos para público infanto/juvenil, o que hoje em dia não é considerado um problema, mas na época parecia ser. Também não era tão forte o engajamento das redes sociais, que hoje praticamente dita o que deve ser lido ou não, e editora ainda estava no começo. Acho que continuamos a série muito por teimosia, minha e da Chirlei. O pessoal sempre perguntava se íamos continuar traduzindo, e a gente acabava dizendo que sim, nem que fosse apenas por encomenda. A Chirlei apostou muito no meu trabalho também, acho que via um potencial que nem eu mesma via, e meu entusiasmo, e me estimulou a continuar por isso. E em 2017, quando estávamos lançando Anne da Ilha, o terceiro livro da série, tivemos a notícia de que haveria uma adaptação baseada nos livros, e isso foi o estímulo que precisávamos para continuarmos até o fim. Ainda assim, o livro 4, Anne de Windy Poplars, foi lançado apenas 1 ano depois do livro 3.

10) A editora publicará também “The Blythes Are Quoted” publicado em 2009?

Eu sinceramente não sei se a Pedrazul tem interesse em publicar este livro, eu nunca discuti isso com a editora, nem a editora com os leitores, então a verdade é que não sei.

11) A primeira tradução para o português do Brasil da obra Anne of Green Gables data de 1939 de autoria de Yolanda Vieira Martins pela Companhia Editora Nacional na Coleção Biblioteca das Moças. Somente 70 anos mais tarde, em 2009, uma segunda tradução foi publicada pela Martins Fontes tendo por tradutores Renée Eve Levie e Maria do Carmo Zanini. A sua tradução desta obra é a terceira. E após a sua, no mínimo, quatro foram publicadas somente em 2019. Você lê outras traduções da obra que pretende traduzir? Você leu alguma tradução de Anne of Green Gables quer seja para o português quer seja para outras línguas?

Não li nenhuma tradução de nenhum dos livros. Sei que a revisora das obras, Carolina Pegorini, leu a edição de 2009, e inclusive a utilizou em seu trabalho de revisão, para não corrermos o risco de plagiar alguma frase, ou parágrafo, ainda que de forma inconsciente. 
12) Como você descreveria seu projeto tradutório para a Obra de Montgomery?

Eu realmente nunca parei para pensar e elaborar um projeto. Eu li os livros antes por acaso, e dessa maneira tinha uma ideia de qual o teor da obra, qual era o "passing" da obra, como se desenvolvia, e tinha uma ideia de como poderia ser saboreado em português. Mas à época, não tinha nenhuma ideia de teoria tradutória, nem de que abordagem seguir. Hoje sei que me utilizo da "Estrangeirização," ou seja, mantenho na língua original termos que considero, após análise, como sendo importantes para que o leitor sinta que está inserido em um contexto não natural ao seu, ou seja, o leitor sente que está lendo uma obra estrangeira. Não traduzo nomes (mesmo os que possuem tradução ao português), e por escolha dos leitores, e editorial da Pedrazul, não traduzimos os pronomes de tratamento "Mrs. Mr. e Miss," para citar exemplos. Em compensação traduzo as expressões idiomáticas, buscando expressões que eram comuns à época no Brasil também, o que se torna muitas vezes um trabalho bem complicado, mas satisfatório para dar a "cara" de obra de época. Busco também palavras que sejam conhecidas, mas algumas que até caíram em desuso no nosso português, para manter a linguagem de época. O que, devo confessar, é uma das coisas que mais amo ao traduzir clássicos, este reencontro com a língua portuguesa como ela era, mas ainda assim, buscando uma maneira de manter a linguagem do livro fluída. A Maud tem uma maneira de escrever comédia que me agrada muito, e logo no próximo capítulo, ela vai para o drama, com a mesma doçura e sensibilidade. Tento manter esse "passing," o mais próximo possível ao original.

13) Há algum trecho ou capítulo que lhe demandou mais atenção ao traduzir? Por que?

Logo no início, quando ainda estava conhecendo o estilo da autora, tinha muita dificuldade para traduzir as descrições de paisagens, flores, plantas específicas da flora canadense, que muitas vezes não tinham tradução, então tinha que buscar nomes de flores que fossem parecidas, para que pudesse ficar mais claro para o público brasileiro. Mas isso foi mais complicado no primeiro livro, onde a autora estava especificamente descrevendo com detalhes o ambiente, e tudo isso sob o ponto de vista da Anne, que sempre é cheio de imaginação, de grandes adjetivos para tudo e todos. Depois, "peguei o jeito" da autora. Algo que sempre acho difícil ao traduzir clássicos de época são as expressões. A Maud escreve muitas personagens campesinas, simplórias, e estas sempre se utilizam de expressões regionalistas e específicas da 
época. Então, para manter este mesmo “ar", sempre tenho que pesquisar expressões que estejam de acordo com o estilo e a época, e isso nem sempre é fácil.

14) Qual dos livros da série você mais gostou de traduzir? Por quê?

Acho que foi Anne e a Casa dos Sonhos, o quinto livro da série, porque já tinha sido o meu favorito ao ler, e eu estava passando por um momento delicioso da minha vida pessoal (um bebê pequeno), e a Anne está, neste livro, passando pela mesma fase. Mas cada um dos livros teve algo de especial.

15) Você assiste ou assistiu a série Anne with en E? Ou, mesmo outras adaptações, quer seja série ou filme? O que te chamou atenção na(s) adaptação(ões) da obra de Montgomery?

Eu assisti a primeira temporada da série Anne With an E. Esta adaptação trouxe consigo toda a aura lúdica que Maud criou com suas palavras, através da imaginação da Anne, e de sua maneira de ver o mundo, quer seja "nas profundezas do desespero", ou em seus "salões de mármore e brilho do sol". Mas achei que a criadora da série, Moira Beckett, exagerou em alguns pontos da personalidade da Anne, e de outras personagens, e modificou a essência das personagens principais também, o que atrapalha um pouco a experiência ao assistir a série para mim, que tenho esse contato mais íntimo com o texto. Acho que é mais que natural que tenhamos, como tradutores, praticamente uma visão de dentro da cabeça do autor, de suas intenções, e o que tinham em mente para suas personagens. E acho que no caso da Anne, fica ainda mais íntima essa relação, pois a gente literalmente acompanha a Anne crescendo, e mudando, durante o curso da vida. Então eu tenho uma visão diferente de quem é a Anne e do que ela faria, e não sei se esta adaptação soube captar essa essência.

Mas acho que esta série teve um papel fundamental para o sucesso destas obras entre as novas gerações, ainda mais no Brasil, onde até muito pouco tempo atrás, ninguém conhecia a autora e pouquíssimas pessoas tinham acesso aos livros. Além disso, a série abordou assuntos delicados, como suicídio, diversidade sexual, diversidade física, diversidade racial, feminismo, bullying etc., que são assuntos amplamente discutidos entre os adolescentes e jovens, os quais a série abordou com muita sabedoria, e de forma lúdica e interessante. Por causa da série, a Anne se tornou um ícone entre a juventude, e eu sou muito grata por isso. Sempre digo, a 
história da Anne precisa ser lida. Portanto, qualquer ação que promova o conhecimento desta personagem e que leve aos livros, se torna positiva em minha opinião.

$\mathrm{Eu}$, pessoalmente, amo os filmes "Anne of Green Gables," de 1985, "Anne of Green Gables - The Sequel” de 1987 e "Anne of Green Gables - The Continuing Story”, lançado em 2000, que, se não me engano, no Brasil se chama “Os Amores de Anne”. Esta série é considerada por canadenses e puristas, e por mim também, como a adaptação mais próxima aos livros. Foi por esta série que eu conheci a personagem Anne, e por isto, esta é minha adaptação favorita. E inclusive, me baseio nos atores desta série quando imagino as situações dos livros, para formar meu próprio “filme”, através da minha imaginação. É dessa série que vem as "vozes na minha cabeça”. O filme de 2006, que tem Martin Sheen no papel de Matthew Cuthbert, eu nunca assisti.

16) Além da Obra de Montgomery, quais outras obras você traduziu?

Eu traduzi, em 2015, o livro Um Coração para Milton, da escritora americana Trudy Brasure, que é uma adaptação/continuação do clássico inglês, de Elizabeth Gaskell, Norte e Sul. Traduzi também um trecho da obra "A Mão de Deus ao Leme," de Enoch de Oliveira, pela Casa Publicadora Brasileira da Igreja Adventista do Sétimo Dia. E traduzi um livro que ainda não foi lançado, chamado Haverim, Como Ensinar Qualquer Coisa a Qualquer Pessoa, do autor inglês Paul Webster, que é um livro teológico.

17) Por fim, o que você diria a tradutores em formação que desejam trabalhar com textos literários?

Leia, leia, leia, leia. Leia livros que gosta, que sempre é a melhor parte, leia livros que te desafiam, leia clássicos brasileiros, que acrescentam uma elasticidade ao nosso uso da língua, que julgo extremamente necessária para qualquer tradutor, e principalmente um tradutor literário. Estude nossa língua, sua gramática, e sua estrutura tão linda. Escreva, escreva, escreva. Traduza, traduza e traduza mais um pouco. Desafie-se.

\footnotetext{
* Patrícia Rodrigues COSTA - Doutora em Estudos da Tradução (2018) pela Universidade Federal de Santa Catarina (UFSC). Mestre em Estudos de Tradução (2013), Bacharel em Agronomia (2014) e Bacharel em Letras/Tradução - Inglês (2008) pela Universidade de Brasília. Licenciada em Letras Inglês (2019) pelo Centro Universitário Estácio de Ribeirão Preto. É pós-doutoranda do Programa de Pós-Graduação em Estudos da
} 
Tradução (POSTRAD) da Universidade de Brasília. É editora assistente da Revista Belas Infiéis desde 2013. Brasília, Distrito Federal, Brasil.

Currículo acadêmico: http://lattes.cnpq.br/9546437584230118

ORCID: https://orcid.org/0000-0002-3254-8914

E-mail: prcosta1986@gmail.com

${ }^{* *}$ Tully EHLERS - Puiggari, Entre Rios, Argentina

LinkedIn: https:/www.linkedin.com/in/tully-ehlers-722b58102/

E-mail: tully.deoliveira@gmail.com 